\title{
OUTCOMES OF WORK-LIFE BALANCE ON JOB SATISFACTION, LIFE SATISFACTION AND MENTAL HEALTH: A STUDY ACROSS SEVEN CULTURES.
}

\author{
JARROD M. HAAR* \\ School of Management \\ Massey University \\ Private Bag 102904 \\ North Shore City, New Zealand \\ email: j.haar@massey.ac.nz
}

\section{MARCELLO RUSSO*}

Department of Management

KEDGE Business School

680 Cours de la Liberation, 33405

Talence cedex (Bordeaux), France

email: marcello.russo@kedgebs.com

\author{
ALBERT SUNE \\ Department of Management \\ Universitat Politècnica de Catalunya \\ Etseiat, C. Colom 11, 08222 \\ Terrassa (Barcelona), Spain \\ email: albert.sune@upc.edu
}

\author{
ARIANE OLLIER-MALATERRE \\ Organisation and Human Resources Department \\ École des Sciences de la Gestion \\ Université du Québec A Montréal \\ 315, rue Sainte-Catherine Est, local R-3490 \\ Montréal (Québec), H2X 3X2 \\ email: ollier.ariane@uqam.ca
}

* =denotes shared first authorship

Acknowledgements: We thank Tammy Allen and other conference attendees for theirhelpful feedback on an earlier version of this paper presented at the International Center for Work and Family 2013 conference. We are also grateful to the anonymous reviewers who gave us insightful suggestions. 


\title{
OUTCOMES OF WORK-LIFE BALANCE ON JOB SATISFACTION, LIFE SATISFACTION AND MENTAL HEALTH: A STUDY ACROSS SEVEN CULTURES
}

\begin{abstract}
This study investigates the effects of work-life balance (WLB) on several individual outcomes across cultures. Using a sample of 1,416 employees from seven distinct populations - Malaysian, Chinese, New Zealand Maori, New Zealand European, Spanish, French, and Italian - SEM analysis showed that WLB was positively related to job and life satisfaction and negatively related to anxiety and depression across the seven cultures. Individualism/collectivism and gender egalitarianism moderated these relationships. High levels of WLB were more positively associated with job and life satisfaction for individuals in individualistic cultures, compared with individuals in collectivistic cultures. High levels of WLB were more positively associated with job and life satisfaction and more negatively associated with anxiety for individuals in gender egalitarian cultures. Overall, we find strong support for WLB being beneficial for employees from various cultures and for culture as a moderator of these relationships.
\end{abstract}

Keywords: work-life balance; collectivism; individualism; gender egalitarianism; crosscultural; job satisfaction; life satisfaction; mental health; anxiety; depression. 


\section{Introduction}

Work-life balance (WLB) is a central concern in everyday discourses (Greenhaus \& Allen, 2011; Greenhaus, Collins, \& Shaw, 2003; Guest, 2002; Kossek, Valcour, \& Lirio, 2014; Maertz \& Boyar, 2011). However, despite its popularity, WLB remains one of the least studied concepts in work-life research (Greenhaus \& Allen, 2011). Valcour (2007) noted that it is "a concept whose popular usage has outplaced its theoretical development" (p. 1513). A reason for this is the field's struggle to agree on a common definition of WLB (Greenhaus \& Allen, 2011). Another reason is that research on the positive individual outcomes of WLB has been relatively slow to accumulate (Greenhaus \& Allen, 2011; Maertz \& Boyar, 2011). In addition, most of the current studies focus on work-family balance, without considering individuals' broader lives including community, leisure, church, sport and other activities (Hall, Kossek, Briscoe, Pichler, \& Lee, 2013). In this study we work with a relatively consensual definition of WLB as being an individual's assessment of how well her or his multiple life roles are balanced (e.g. Greenhaus \& Allen, 2011; Haar, 2013; Kossek et al., 2014). We aim to contribute to WLB research at solidifying the concept of WLB by examining its relationship with four important individual outcomes: job satisfaction, life satisfaction, anxiety, and depression.

Furthermore, we know very little about the impact of cultures on the relationship between WLB and individual outcomes. A recent review of cross-national work-life research has identified only two cross-cultural studies focusing on WLB compared with 29 focusing on conflict and nine on enrichment; the only cultural dimension examined in these studies was gender egalitarianism (Ollier-Malaterre, 2014). This is a clear shortcoming of current research given that numerous calls have been issued to broaden the scope and ambition of work-life research by conducting cross-national studies that consider the impact of multiple cultural dimensions (Greenhaus \& Allen, 2011; Kossek, Baltes, \& Matthews, 2011; Ollier-Malaterre, Valcour, Den Dulk, \& Kossek, 2013; Poelmans, 2005). In this paper we address this gap by testing whether the relationships between WLB, job satisfaction, life satisfaction, anxiety, and 
depression are moderated by two important cultural dimensions: (1) individualism/collectivism (I/C) and (2) gender egalitarianism (GE). Based on a sample of 1,416 employees from seven distinct cultures -Malaysian, Chinese, New Zealand Maori, New Zealand European, Spanish, French, and Italian, we find strong support for direct effects of WLB across all of the study's samples. We also find moderating effects of I/C and GE on these relationships.

Our study makes three important contributions to the literature. First, we contribute to establish WLB as a solid construct that sheds light on major individual outcomes, thereby encouraging future research on WLB as a way to better understand a complex work-life interface, and encouraging practitioners to assess their employees' WLB as part of their HR efforts. Second, our study is unique in the burgeoning body of cross-cultural research on the work-life interface (for a review, see Ollier-Malaterre, 2014) since it is the first, to our knowledge, to focus on WLB rather than work-family conflict or work-family enrichment and to have collected evidence that two dimensions of national culture, i.e. I/C and GE, moderate the relationships between WLB and individual outcomes. The finding that WLB has beneficial outcomes for individuals across seven distinct cultures lends further support to the construct of WLB. Third, our study provides evidence that work-life concepts that originated in Western cultures are generalizable beyond these cultures - we do so by including cultures of growing interest in the literature (e.g. Malaysia and China) as well as understudied cultures (e.g. New Zealand European and Maori).

\section{Theoretical background and hypotheses}

\subsection{Work-life balance}

Consistent with recent theoretical advancements (e.g. Frone, 2003; Greenhaus \& Allen, 2011; Haar, 2013; Kossek et al., 2014), we conceptualize WLB as an individual's perceptions of how well his or her life roles are balanced. This conceptualization of individuals subjectively gauging balance between the work and the rest of their life (Guest, 2002) is in contrast with prevailing views that considered balance to be equivalent to low role conflict (Duxbury \& 
Higgins, 2001), to high role enrichment (Frone, 2003) or to an equal division of time and attention among the several roles that compose an individual's life system (Marks \& MacDermid, 1996). Our definition is grounded in the perception-centered approach that considers work-life balance to be a holistic concept, unique for each person and that depends upon his or her life values, priorities and goals (Kossek et al., 2014).

With a few exceptions (see Lyness \& Judiesch, 2014; Hill, Yang, Hawkins, \& Ferris, 2004), cross-national research has mostly neglected work-life balance. However, there is general consensus among scholars that work-life balance is highly valued by nearly all employees (Kossek et al., 2014) and it has important implications on people's well-being and work productivity all over the world (Lyness \& Judiesch, 2014). Interestingly, research conducted by IBM has shown that people's nationality does not translate in differences in the expressed desire for work-life balance (Hill et al., 2004). Regarding the effects of WLB, extant research shows that people who perceive balance between their work and life roles tend to be more satisfied of their life and report better physical and mental health (Brough et al., 2014; Carlson, Grzywacz, \& Zivnuska, 2009; Greenhaus et al., 2003; Ferguson, Carlson, Zivnuska, \& Whitten, 2012; Haar, 2013; Lunau, Bambra, Eikemo, van der Wel, \& Dragano, 2014). Building on these premises, in this article we hypothesize, for two reasons, that WLB will be positively related to job and life satisfaction and negatively related to mental health universally for all employees.

First, we believe that individuals who experience WLB may be more satisfied of their job and life "because they are participating in role activities that are salient to them" (Greenhaus et al., 2003; p. 515). Second, we believe that balanced individuals may be mentally healthier because they experience a sense of harmony in life and optimal psychophysiological conditions which enable them to meet the long-term demands of work and nonwork roles (Greenhaus et al., 2003). This may lead them to be less apprehensive about their abilities to conciliate work and nonwork commitments and also less prone to develop ruminating thoughts 
about the lack of balance in life that can deplete their physical and mental resources (Rothbard, 2001). Accordingly, we hypothesize that the benefits of WLB will be universal across all country cultures.

H1: WLB will be positively related to job satisfaction across cultures.

H2: WLB will be positively related to life satisfaction across cultures.

H3: WLB will be negatively related to anxiety across cultures.

H4: WLB will be negatively related to depression across cultures.

\subsection{Moderating effects of individualism/collectivism}

$\mathrm{I} / \mathrm{C}$ is the cultural dimension that has received the "lion's share of attention as a predictor of cultural variation” (Brewer \& Chen, 2007, p. 133). This dimension is also a powerful moderator of employee cross-cultural studies (Ramamoorthy \& Flood, 2002), including work-family studies (Spector et al., 2004, 2007; Hill et al. 2004). I/C reflects whether people view themselves as independent (individualists) or are tightly linked to others as part of groups (collectivists) (Triandis, 1995). We follow House, Hanges, Javidan, Dorfman, and Gupta (2004), where in-group collectivism is defined as "the degree to which individuals express pride, loyalty, and cohesiveness in their organizations or families” (p. 30). In essence, in individualistic cultures people tend to prioritize personal interests over common goals, whereas in collectivistic cultures people tend to prioritize common goals, including family ones, over personal needs.

A recent review of cross-cultural work-life research found no studies linking I/C and WLB (Ollier-Malaterre, 2014). However, there is considerable research showing that workfamily conflict is less detrimental to individuals in collectivistic than in individualistic cultures (Lu et al., 2010; Lu, Gilmour, Kao, \& Huang, 2006; Spector et al., 2004, 2007; Yang, Chen, Choi, \& Zou, 2000). This can be explained by the presence of different appraisal mechanisms in different cultures (Aycan, 2008). In collectivistic cultures, work is viewed as a way of supporting a family (Redding \& Wong, 1986; Redding, 1993) such that people tend to deem 
work-family conflict as an inevitable life experience to promote wealth and financial stability for the family (Aryee, Luk, Leung, \& Lo, 1999; Spector et al., 2007). Instead, in individualistic cultures work is generally viewed as an individual achievement that contributes to selfactualization and that is incompatible with family roles (Spector et al., 2004, 2007); therefore people deem work-family conflict to be problematic and a threat to personal health and wellbeing (Aycan, 2008). Drawing on these assumptions, we expect WLB to be less strongly related to positive outcomes in collectivistic than in individualistic cultures. We reason that achieving balance should be more pivotal for people in individualistic cultures, as it is considered more essential in individualistic societies to live one's life to the fullest and to recover from the stress and strains associated with work roles (Spector et al., 2004, 2007). Instead, people in collectivistic cultures tend to perceive role imbalance in a less problematic way as they view it as an inevitable cost in promoting family well-being (Aryee et al., 1999). From this we can infer that individuals in individualistic cultures will benefit more from experiencing greater WLB as achieving WLB is more of a focus in their cultures and thus will weigh more towards their satisfaction and mental health. Accordingly,

H5: Individualism/Collectivism will moderate the relationship between WLB and individual outcomes, such that:

H5. The positive relationship between WLB and (a) job satisfaction and (b) life satisfaction will be stronger in countries higher in individualism.

H5. The negative relationship between WLB and (c) anxiety and (d) depression will be stronger in countries higher in individualism.

\subsection{Moderating effects of gender egalitarianism}

GE reflects the presence of "beliefs [in the society] about whether members' biological sex should determine the roles that they play in their homes, business organisations, and communities" (House et al., 2004, p. 347). Low GE cultures are characterised by beliefs in the traditional gendered division of labour, which depict men as breadwinners and women as 
caregivers and homemakers (Wood \& Eagly, 2002). Notably, extant research has shown that in high GE cultures there is less adhesion to traditional gender patterns and it is considered personally and socially acceptable that both women and men pursue their own life goals and struggle to guarantee the desired level of involvement in both work and non-work roles (Lyness \& Judiesch, 2014).

Research on the influence of GE on the work-life interface is still at a very early stage and cross-national research in particular is very scarce (Lyness \& Kropf, 2005; Lyness \& Judiesch, 2014). Lyness and Judiesch (2008) found a GE moderated relationship, with managers' self-rating of WLB more positively related to peer's and supervisor's advancement potential rating for female managers in high gender egalitarian cultures and for men managers in low gender egalitarian cultures. In this paper, we hypothesize that WLB will be associated with higher job and life satisfaction and lower anxiety and depression for individuals living in high GE cultures than for those living in low GE cultures. We contend that living in cultures where both men's and women's work and non-work role involvement is encouraged and considered socially acceptable can amplify the beneficial effects of WLB (Corrigal \& Konrad, 2006). Conversely, in low GE cultures we believe that achieving WLB may be less beneficial as traditional gender role prescriptions are prevailing and may instil in the population the expectations that men should prioritize work over the family and women should do the opposite. Thus, experiencing WLB might not be perceived as beneficial as it might be in high GE cultures because it is inconsistent with societal expectations about gender division of labour. Accordingly,

H6: Gender egalitarianism will moderate the relationship between WLB and individual outcomes, such that:

H6. The positive relationship between $W L B$ and (a) job satisfaction and (b) life satisfaction will be stronger in countries higher in GE. 
H6. The negative relationship between WLB and (c) anxiety and (d) depression will be stronger in countries higher in GE.

Figure 1 illustrates our general structural model.

\section{INSERT FIGURE 1 ABOUT HERE}

\section{Method}

\subsection{Samples and procedures}

Data were collected from six countries (New Zealand, Spain, France, Italy, Malaysia and China) and included seven samples. Two separate samples were collected from New Zealand: Maori (indigenous people of New Zealand) and New Zealand European, the largest population group (equivalent to Caucasians in the US). Table 1 illustrates the descriptive data of the seven samples as well as of the combined sample. The authors personally collected data from four countries including both samples from New Zealand, while two research assistants native of China and Malaysia collected data from these countries. We used our networks to generate the largest number of employees from a broad range of organizations. Then, following basic principles of snowball sampling (Biernacki \& Waldorf, 1981), we asked recruited participants to recommend participation in the research to their contacts. The necessary requirement to be included in the sample was being engaged in a full-time job. All surveys where English is not the first language were translated into the native language (e.g., French, Italian, Mandarin, etc.) and then back-translated to minimize translation error (Brislin, 1980).

\section{INSERT TABLE 1 ABOUT HERE}

Overall, the combined sample includes 1,416 employees of whom 546 come from collectivistic cultures (Maori, Malaysia and China). The average age was 37.6 years, gender was fairly evenly split (55\% female) and the majority were married (70\%) and parents (61\%).

\subsection{Measures}

All samples used the same items, and except where noted, all items were rated on a 5point scale $(1=$ strongly disagree to $5=$ strongly agree $)$. Items were averaged to produce 
composite indicators, with higher scores indicating higher values of the given measure. All measures achieved adequate reliability within each country sample (all $\alpha>.70$ ). We thus combined the seven samples to test our hypotheses (with alphas reported in Table 3).

3.2.1 WLB was measured using a 3-item measure by Haar (2013). A sample item is "I manage to balance the demands of my work and personal/family life well”. As this measure is still new, we conducted factor analysis (principal components, varimax rotation) for each distinct population and on the combined sample. The 3-items loaded onto a single factor universally across all seven samples with eigenvalues greater than 1; accounting for sizeable amounts of the variance and achieving adequate reliability in all samples as shown in Table 2.

\section{INSERT TABLE 2 ABOUT HERE}

3.2.2. Job Satisfaction was measured using 3-items by Judge, Bono, Erez and Locke (2005). A sample question is "Most days I am enthusiastic about my work".

3.2.3. Life Satisfaction was measured using the 5-item scale by Diener, Emmons, Larsen and Griffin (1985). A sample question is "In most ways my life is close to ideal".

\subsubsection{Anxiety and Depression were assessed using 6-items by Axtell and colleagues (2002).}

This measure has been shown to have good psychometric properties (Haar, 2013; Spell \& Arnold, 2007). The items were rated on a 5-point scale $(1=$ never to $5=$ all the time $)$. Presented with three adjectives for each measure, respondents were asked to indicate how often each adjective applied to them while they were at work.

\subsubsection{Collectivism was assessed by coding cultures using GLOBE scores for in-group} collectivism (House et al., 2004). This approach is superior to the typical dichotomous approach often used in the work-family literature (e.g. Spector et al., 2004), as it offers a range of scores that better reflect cultural variations across countries. New Zealand (European) was rated the most individualistic (3.67), and China the most collectivistic (5.8). One issue we came across was that the GLOBE study does not list New Zealand Maori as a separate culture than the rest of the New Zealand population. Indeed, while making up $14 \%$ of the population, it is 
grouped into New Zealand culture as a whole. Since Maori have been found to have a strong collectivistic culture (Brougham \& Haar, 2013; Haar, Roche, \& Taylor, 2012) and prior research has widely documented that is distinct from the individualistic New Zealand European (Haar \& Brougham, 2011; Podsiadlowski \& Fox, 2011), we decided to use for this particular ethnic group the same score as in China (5.8). This score aligns with the GLOBE collectivism score for the Southern Asia cluster (Gupta, Surie, Javidan, \& Chhokar, 2002), which provides an overall score for the six countries that make up the cluster. As such, we suggest that this provides a useful proxy for a collectivistic culture that aligns well with Maori (Brougham \& Haar, 2013). Furthermore, we tested our model without including the Maori sample and we found no noticeable differences in our results. Therefore, we suggest that including the Maori sample does not distort our overall findings and provides an additional rich new population to explore.

3.2.6. Gender egalitarianism was assessed by coding cultures using the GLOBE scores (House et al., 2004). China was rated the least gender egalitarian (3.68) with Italy the highest (4.88). As with collectivism, this approach is superior to the dichotomous approach but similarly, does not have a score for Maori. We followed the same logic outlined above for collectivism and used the same score as in China.

3.2.7. Control variables. In line with prior research (Carlson et al., 2009), we included gender (coded as $1=$ female and $0=$ male) and work-family conflict as covariates in our analyses. We used 6-items from the scale by Carlson, Kacmar and Williams (2000) to measure work-tofamily conflict (WFC) and family-to-work conflict (FWC). A sample item for WFC is "I have to miss family activities due to the amount of time I must spend on work responsibilities" and a sample item for FWC is "The time I spend on family responsibilities often interfere with my work responsibilities". 


\subsection{Measurement Models}

To confirm the separate dimensions of the various study's measures in the combined sample, a CFA was run in SEM using AMOS 20.0. We followed Williams, Vandenberg, and Edwards' (2009) recommendations regarding the goodness-of-fit measures: (1) the comparative fit index (CFI $\geq .95)$, (2) the root-mean-square error of approximation (RMSEA $\leq .08)$, and (3) the standardized root mean residual $(\mathrm{SRMR} \leq .10)$. The hypothesized measurement model included seven distinct factors: WLB, WFC, FWC, job satisfaction, life satisfaction, anxiety and depression, and resulted in a good fit to the data, meeting all minimum requirements: $\chi^{2}$ $(209)=771.0(p=.000)$, CFI $=.97$, RMSEA $=0.05$ and SRMR $=0.04$. The goodness of the hypothesized model was also confirmed by testing alternative models as advocated by Hair, Black, Babin and Anderson (2010). Overall, the hypothesized measurement model did fit the data better than all the alternative models (results available from authors), which resulted in all alternative models being a significantly poorer fit $(\mathrm{p}<.001)$. This confirmed WLB to be a distinct construct from WFC and FWC.

Multi-Group Analysis CFA was conducted to establish measurement invariance between the seven samples (Bou \& Satorra, 2010). While SEM model comparisons typically test chi-squared differences, this heavy reliance has been criticized (Schmitt \& Kuljanin, 2008). This is because large samples and complex models are highly susceptible to significant changes in the chi-squared value. Cheung and Rensvold (2000) offered a number of alternative goodness-of-fit measures and we focus on the RMSEA because Meade and Kroustalis (2006) show this measure is not affected by model complexity. Our model showed measurement equivalence as the difference in RMSEA between the seven sample constrained and unconstrained model were very small at .002 (0.022 versus 0.024$)$, which is below the critical value established by Cheung and Rensvold (2000). As such, this gives us confidence that the combined sample has metric invariance and can be analysed as a combined sample.

\subsection{Analysis}


Hypotheses were tested using SEM in AMOS v.20 to assess the direct (Hypotheses 1-4) and potential moderating effects of I/C (Hypotheses 5) and GE (Hypotheses 6), due to SEM being found to be superior to regression analysis (Cheng, 2001; Iacobucci, Saldanha, \& Deng, 2007). Aligned with recommendations by Aiken and West (1991), the interaction terms were zscored. Because the size of the structural models became overly complex when we included both moderators in the models, we ran two sets of moderation models for $\mathrm{I} / \mathrm{C}$ and GE, respectively. For moderation analyses in SEM, all three z-scored WLB items were multiplied by the single GLOBE variable (I/C or GE score) to create a new variable in each model: (1) the interaction of WLB x I/C, and (2) the interaction of WLB x GE.

\section{Results}

\subsection{Correlations}

Descriptive statistics and intercorrelations for the study variables in the combined sample are shown in Table 3.

\section{INSERT TABLE 3 ABOUT HERE}

The four outcome variables were all significantly correlated to each other (all $p<.01$ ) in the expected directions. WLB, WFC and FWC were also correlated (all $\mathrm{p}<.01$ ). In addition, $\mathrm{I} / \mathrm{C}$ was significantly correlated to $\operatorname{WLB}(\mathrm{r}=.08, \mathrm{p}<.01)$, anxiety and depression (both $\mathrm{r}=-.14$, $\mathrm{p}<.01)$, while GE was significantly correlated to WLB $(\mathrm{r}=-.09, \mathrm{p}<.01)$, job satisfaction $(\mathrm{r}=$ $.18, \mathrm{p}<.01)$, anxiety $(\mathrm{r}=.34, \mathrm{p}<.01)$ and depression $(\mathrm{r}=.15, \mathrm{p}<.01)$. Furthermore, $\mathrm{I} / \mathrm{C}$ and GE were significantly correlated to each other $(\mathrm{r}=-.38, \mathrm{p}<.01)$.

\subsection{Structural Models}

The two moderated SEM models included an additional interaction term to the measurement model: (1) WLB x I/C, and (2) WLB x GE. Consequently, both models were larger than the original measurement model. Despite this, the moderated structural models still resulted in a good fit to the data, meeting all minimum requirements for I/C (model 1): $\chi^{2}(307)$ $=970.4(\mathrm{p}=.000), \mathrm{CFI}=0.96, \mathrm{RMSEA}=0.04$ and SRMR $=0.03$, and for GE $(\operatorname{model} 2): \chi^{2}$ 
$(307)=1145.1(\mathrm{p}=.000), \mathrm{CFI}=0.96, \mathrm{RMSEA}=0.04$ and SRMR $=0.04$. Table 4 highlights the significant direct and moderation effects from both models.

INSERT TABLES 4 \& 5 ABOUT HERE

Aligned with the recommendations of Grace and Bollen (2005), unstandardized regression coefficients are presented in our tables. Table 4 shows that WLB was significantly related to job satisfaction (path coefficient $=.50, \mathrm{p}<.001$ ) and life satisfaction (path coefficient $=.52, \mathrm{p}<.001)$, supporting Hypotheses 1 and 2. WLB was also significantly linked with anxiety (path coefficient $=-.37, \mathrm{p}<.001)$, and depression $($ path coefficient $=-.38, \mathrm{p}<.001)$, supporting Hypotheses 3 and 4. Furthermore, we re-analysed the data separately for all seven samples and these confirmed the effects held in all country samples (see Table 5). Importantly, these effects were found after controlling for WFC and FWC.

Model 1 explored I/C as a moderator, and it was directly and significantly related to both anxiety and depression (both path coefficient $=-.10, \mathrm{p}<.001$ ). Significant interaction effects were found between WLB and I/C towards job satisfaction (path coefficient $=-.12, \mathrm{p}<$ .01 ) and life satisfaction (path coefficient $=-.11, \mathrm{p}<.01$ ). Model 2 explored GE as a moderator, and it was directly and significantly related to job satisfaction (path coefficient $=.08, \mathrm{p}<.001$ ), anxiety $($ path coefficient $=.29, \mathrm{p}<.001)$, and depression $($ path coefficient $=.10, \mathrm{p}<.001)$. Significant interaction effects were found between WLB and GE towards job satisfaction (path coefficient $=.05, \mathrm{p}<.05)$, life satisfaction (path coefficient $=.10, \mathrm{p}<.001)$, and anxiety (path coefficient $=-.09, \mathrm{p}<.01)$

\subsection{Interaction plots}

To provide a better understanding of the interaction effects, plots are presented in Figures 2 to 4.

\section{INSERT FIGURES 2 TO 4 ABOUT HERE}

The interactions for I/C on job and life satisfaction (Figure 2) are almost identical and are thus reported together. They show that there are significant differences between respondent 
groups, with respondents living in individualistic cultures reporting higher levels of satisfaction (both job and life) at low levels of WLB compared to respondents living in collectivistic cultures. At high levels of WLB, respondents living in individualistic cultures reported stable levels of job and life satisfaction, while respondents living in collectivistic cultures reported significantly less job and life satisfaction, in line with our expectations. Overall, employees living in individualistic cultures reported significantly higher job and life satisfaction as expected, supporting hypotheses $5 \mathrm{a}$ and $5 \mathrm{~b}$. Results provided no support for hypotheses $5 \mathrm{c}$ and $5 \mathrm{~d}$.

The interactions for GE on job and life satisfaction (Figure 3) are almost identical and again, we report these grouped together. They show that there are significant differences between respondent groups, with respondents living in high gender egalitarian cultures reporting higher levels of job and life satisfaction at low levels of WLB compared to respondents living in less GE cultures. At high levels of WLB, all respondents reported higher levels of job and life satisfaction, but respondents in high GE cultures reported significantly higher levels of job satisfaction and life satisfaction than those living in less GE cultures. Overall, employees living in GE cultures reported significantly higher levels of job satisfaction and life satisfaction. Figure 4 shows there are no significant differences towards anxiety at low levels of WLB between respondent groups at low or high GE. At high levels of WLB, all respondents report lower anxiety although those respondents in high GE cultures reported a steeper decrease compared to respondents in low GE cultures. These findings support hypotheses $6 \mathrm{a}, 6 \mathrm{~b}$, and $6 \mathrm{c}$.

Overall, the structural model accounted for moderate amounts of variance for all outcomes, and these were identical between the two moderation models for most outcomes: job satisfaction $\left(\mathrm{R}^{2}=.25\right)$, life satisfaction $\left(\mathrm{R}^{2}=.33\right)$, and depression $\left(\mathrm{R}^{2}=.18\right)$. Only towards anxiety were there major differences in variance, with the GE model accounting for far greater variance $\left(\mathrm{R}^{2}=.28\right)$ than the $\mathrm{I} / \mathrm{C}$ model $\left(\mathrm{R}^{2}=.18\right)$. 


\subsection{Supplementary analyses}

Finally, an ANOVA test was conducted to examine the reported levels of WLB between the seven samples. Although the ANOVA test is important to know that at least two groups differ, it does not identify the groups that actually differ. Therefore, we run a multigroup mean comparison between all distinct populations to identify the pattern of differences in our results by using the Fisher Least Significant Difference (LSD) and Student-Newman-Keuls tests as post-hoc analyses. The LSD test indicates which group configurations significantly differ from one another, whereas the Student-Newman-Keuls is a sequential test designed to indicate which groups are significantly differ from all the others. It orders mean scores from the lowest to the highest and compares pairs of groups for significant differences. Overall, the F-tests (results available from authors) revealed the presence of a significant difference for WLB across sample between at least two distinct populations. The Student-Newman-Keuls test revealed that the only significant difference existed between the Spanish and Italian sample, with Spanish respondents who reported significant higher levels of WLB $(M=3.47$, s.d. $=$ $0.76)$ than the Italian respondents $(M=3.24$, s.d. $=0.79)$. Notably, the Maori sample $(M=3.56$, s.d. $=0.94)$ reported significantly higher levels of WLB than the samples from Italy $(p<.000)$, New Zealand $(p<.000)$, France $(p<.01)$, Malaysia $(p<.05)$, but not China $(p=.052)$.

\section{Discussion and conclusions}

The present study investigated the outcomes of WLB on job satisfaction, life satisfaction, anxiety and depression across seven distinct cultures. More specifically, we explored whether individualism/collectivism (I/C) and gender egalitarianism (GE) moderated the relationship between WLB and these four outcomes. We found strong and consistent support across all cultures for WLB to be associated with outcomes in the expected directions, albeit with some differences related to variations in national culture. Regarding $\mathrm{I} / \mathrm{C}$, as expected, we found that high levels of WLB were more positively associated with job and life satisfaction for individuals in individualistic cultures, compared with those in collectivistic 
cultures. As such, we provide the first or one of the first empirical evidence that the outcomes of WLB can be better understood by including I/C in the analysis. A possible explanation for this result is linked to the importance that WLB assumes in individualistic cultures where it is a critical component influencing individuals' subjective assessment of their overall quality of their work and life experiences (Spector, 2004, 2007). Furthermore, in individualistic cultures individuals generally have full responsibility for achieving WLB. Therefore, it is possible that, once achieved, WLB may lead to higher feelings of satisfaction in life due to contentent linked to this achievement. Notably, I/C did not significantly moderate the relationship between WLB and anxiety or depression. This is an interesting finding that can be understood in light of the broader network and greater level of social/family support usually experienced by individuals in collectivistic cultures that may help them to cope better with life adversities (Powell, Francesco, \& Ling, 2009).

Regarding GE, we found that the beneficial effects of WLB on job and life satisfaction were most salient for individuals living in highly gender egalitarian cultures. This suggests that people in high GE cultures tend to be more satisfied with their job and life when experiencing high WLB than people in low GE cultures. This result is remarkable as this is the first study that documents the presence of differentiated outcomes of WLB across cultures that vary in their levels of GE. A possible explanation for this result is that in high GE cultures there is less adhesion to traditional gender role beliefs and therefore both women and men can perceive equal opportunities to pursue personal and professional life goals (House et al., 2004). Importantly, in such cultures there is higher social approval and more tolerance toward the individual's desire to balance work and non-work roles according to personal life preferences and values without having to sacrifice one domain over the others (Corrigal \& Konrad, 2006; Lyness \& Kropf, 2005). As a result, individuals may feel more satisfied when experiencing WLB as it is consistent with both personal and societal values and beliefs. 
GE also moderated the relationship between WLB and anxiety. The negative relationship between WLB and anxiety was stronger for those living in high GE cultures. This implies that achieving WLB in high GE cultures is likely to enhance the beneficial effects of role balance on mental health. In line with our knowledge that individuals tend to internalize societal gender norms of the country they live in (Eagly \& Wood, 2012), this finding indicates that there may be less mental pressure and anxiety for those achieving greater WLB in high GE cultures, indicating the presence of higher acknowledgement of benefits associated with greater role balance. It is also important to note that the low levels of anxiety for people living in high GE cultures may depend on the fact that in such cultures, people are more likely to engage in activities that are functional to experience detachment from work and replenish mental and physical energies (Larson, Verma, \& Dworkin, 2001).

\subsection{Theoretical contributions}

The present study contributes to the emerging WLB literature in several ways. The present study makes significant contributions to the work-life literature. First, we strengthen research on WLB by establishing its relationship with positive outcomes for individuals, which holds after controlling for work-family conflict. This supports the insightfulness of the perception-centered approach characterizing WLB research. It extends prior work conceptualizing WLB as a holistic construct (Kossek et al., 2014; Greenhaus \& Allen, 2011) being different than work-family conflict and enrichment (Carlson et al., 2009; Greenhaus \& Allen, 2011; Valcour, 2007). We believe that this will help to encourage future research on WLB, and this is important because WLB, as a concept distinct from work-life conflict and work-life enrichment (Valcour, 2007), has the potential to shed light on the complexity of the work-life interface. Our study also emphasizes the importance to focus on work-life balance rather than on work-family balance, as the former term reflects more truthfully the myriads of personal life situations and role involvement decisions that nowadays characterize the contemporary society (Hall et al., 2013). This is consistent with major trends in work-life 
research emphasizing WLB to be a broad issue relevant for all working people (Haar, 2013; Kossek et al., 2014).

Second, this is one of the first studies that explores the outcomes of WLB across several countries and considers the influence of two distinct cultural dimensions, namely individualism/collectivism and gender egalitarianism. This is important as we compare countries that present noticeable differences with regard to their values, assumptions, norms, and belief systems about the gender roles. Thus, our paper enriches comparative work-life research at the individual level and contributes to bridge the macro-micro gap between countrylevel contexts and individual-level variables (Bamberger, 2008; Ollier-Malaterre et al., 2013). Moreover, while a couple of studies have explored the relationship between WLB and GE (e.g., Lyness \& Judiesch, 2014), this is the first study, to our knowledge, that considers the moderating role of $\mathrm{I} / \mathrm{C}$ on the positive effects generated by WLB. This is noteworthy given that $\mathrm{I} / \mathrm{C}$ represents one of the most studied dimension in cross-cultural research (Brewer \& Chen, 2007) and is an important boundary condition of our model explaining why people living in different countries perceive the benefits of WLB to greater or lesser extent. Following recent recommendations in cross-cultural research (e.g., Taras, Rowney, \& Steel, 2009), we used GLOBE scores for $\mathrm{I} / \mathrm{C}$ and $\mathrm{GE}$ as these are reliable and objective instruments for quantifying cultural differences (House et al., 2004).

Third, we tested WLB effects in some settings of growing interest in the literature (e.g. Malaysia and China) and in some understudied settings and (e.g. New Zealand European and Maori). Thus, this article contributes to establish the generalizability of work-life concepts and measures developed in Western countries to other regions of the world (Kossek \& OllierMalaterre, 2013; Ollier-Malaterre et al., 2013; Powell et al., 2009). This is important given that WLB has considerable implications for people all around the world (Hill et al., 2004; Lyness \& Judiesch, 2014). Our finding that the direct effects of WLB hold across all of the study's samples aligns with research pointing out the universal benefit of the work-life interface (Hill et 
al., 2004; Poelmans et al., 2003; Shaffer, Joplin, \& Hsu, 2011; Spector et al., 2007; Spector et al., 2004). However, our finding that two dimensions of national culture (I/C and GE) moderate the relationships between WLB and individual outcomes highlights the need to include cultural dimensions in research designs.

\subsection{Practical implications}

Our findings imply that achieving WLB may hold the key to greater job and life satisfaction, and diminished mental health issues, and this may hold in many countries. This has important implications for organizations that should make sure to assess their employees' WLB in addition to measuring their work-life conflict. Organizations should invest in promoting WLB by implementing work-life policies, such as flexible working hours, and by embracing a supportive work culture that encourages employees to use the work-life policies that are available in the organization (Allen, 2001; Eaton, 2003; Hammer, Kossek, Anger, Bodner, \& Zimmerman, 2011). In addition, encouraging employees to recognize and celebrate their success in balancing roles (when achieved) and to elongate the time frame upon which they to gauge their work-life balance (Marsh, 2011) is also critical to foster greater benefits through understanding the potential changing nature of WLB. This may be particularly important in individualistic cultures and in high gender egalitarian cultures where work-life balance seems to be especially beneficial. Moreover, this can also prevent - especially in individualistic cultures - that employees become frustrated when experiencing temporary situations of role imbalance.

\subsection{Limitations, future research and conclusions}

While the present study encompasses seven distinct samples across six countries, a limitation is the cross-sectional, self-report nature of the data, although this approach is common in other work-family cross-cultural studies (Greenhaus \& Allen, 2011; Spector et al., 2007). To alleviate this limitation we conducted higher order statistical approaches (i.e., CFA) using SEM to confirm the distinct nature of our measures. Furthermore, Kenny (2008) suggests 
that SEM does somewhat mitigate the potential bias related to the presence of common method variance. Similarly, testing for moderation effects also reduces the chances for common method variance (Evans, 1985). In addition, as advocated by Haar (2013), a self-report approach is needed to accurately tap the perception-centered nature of WLB. While additional secondary source data (e.g., supervisor, partner) would be preferable, it was prohibitively difficult to gain such data across a wide range of countries and individuals. As such, the data collected here are similar to that undertaken in other cross-cultural studies, but the CFA and structural analysis run in our study provide some unique statistical contributions, and the moderation analyses also help offsets such limitations.

The present study has implications for future studies, especially cross-cultural studies in the work-life research areas. We hope that it will encourage research based on the concept of WLB, which is an important concept shedding light in job and life satisfaction as well as mental health, and which is more generalizable across cultures that what its Western origin presumed. While our study used robust scores for I/C and GE, it has been noted that individuallevel allocentrism and idiocentrism may make some individuals more sensitive to cultural contexts than others (Triandis, Leung, Villareal, \& Clack, 1985; Wang, Lawler, Walumbwa, \& Shi, 2004). Therefore future studies should strive to measure both culture-level and individuallevel of I/C and GE. Furthermore, there is to date no research investigating the role that other cultural dimensions may play in the relationship between WLB and outcomes. In particular, we encourage researchers to include in future studies the four other dimensions identified in a recent review as extensively impacting work-life conflict, enrichment and balance (OllierMalaterre, 2014): i.e. power distance, uncertainty avoidance, humane orientation (House et al., 2004) and specificity/diffusion (Trompenaars \& Hampden-Turner, 1998). This area of research is almost void and opens avenues for many fruitful studies.

In conclusion, the present study emphasizes the crucial role that WLB plays in promoting greater job and life satisfaction and better mental health across employees in 
different cultures. It also points out that culture, in this study I/C and GE, moderates these relationships. Taken together, the findings of this study offer a fresh and nuanced picture on similarities and differences across cultures, which we hope will encourage future studies in the growing field of comparative work-life research.

\section{References}

Aiken, L. G., \& West, S. G. (1991). Multiple Regression: Testing and Interpreting Interactions. Newbury Park CA: Sage.

Allen, T. D. (2001). Family-Supportive Work Environments: The Role of Organizational Perceptions. Journal of Vocational Behavior, 58(3), 414-435.

Aryee, S., Luk, V., Leung, A., \& Lo, S. (1999). Role Stressors, Interrole Conflict, and WellBeing: The Moderating Influence of Spousal Support and Coping Behaviors among Employed Parents in Hong Kong. Journal of Vocational Behavior, 54(2), 259-278.

Aycan, Z. (2008). Cross-cultural perspectives to work-family conflict. In K. Korabik, D. Lero and D. Whitehead (Eds.), Handbook of work-family integration (pp. 359-371). Cambridge, Cambridge University Press.

Axtell, C., Wall, T., Stride, C., Pepper, K., Clegg, C., Gardner, P., \& Bolden, R. (2002). Familiarity breeds content: The impact of exposure to change on employee openness and well-being. Journal of Occupational and Organizational Psychology, 75, 217-231.

Bamberger, P. (2008). Beyond contextualization: Using context theories to narrow the micromacro gap in management research. Academy of Management Journal, 51(5), 839-846.

Biernacki, P., \& Waldford, D. (1981). Snowball sampling: Problems and techniques of chain referral sampling. Sociological Methods and Research, 10(2), 141-163.

Bou, J.C., \& Satorra, A. (2010). A Multigroup Structural Equation Approach: A Demonstration by Testing Variation of Firm Profitability Across EU Samples. Organizational Research Methods, 13(4), 738-766.

Brewer, B. M., \& Chen, Y. R. (2007). Where (who) are collectives in collectivism? Toward conceptual clarification of individualism and collectivism. Psychological Review, 114(1), $133-151$.

Brislin, R. W. (1980). Translation and content analysis of oral and written materials. In H. C. Triandis and J. W. Berry (Eds.), Handbook of cross-cultural psychology, vol. 2Methodology (pp. 389-444), Boston: Allyn and Bacon. 
Brough, P., Timms, C., O'Driscoll, M. P., Kalliath, T., Siu, O., Sit, C., \& Lo, D. (2014). Worklife balance: a longitudinal evaluation of a new measure across Australia and New Zealand workers. The International Journal of Human Resource Management, DOI: 10.1080/09585192.2014.899262

Brougham, D., \& Haar, J. (2013). Collectivism, cultural identity and employee wellbeing: A study of New Zealand Maori. Social Indicators Research. 114(3), 1143-1160.

Carlson, D. S., Kacmar, K., \& Williams, L. J. (2000). Construction and initial validation of a multidimensional measure of work-family conflict. Journal of Vocational Behavior, 56, 249-276.

Carlson, D. S., Grzywacz, J. G., \& Zivnuska, S. (2009). Is work-family balance more than conflict and enrichment? Human Relations, 62(10), 1459-1486.

Cheng, E. (2001). SEM being more effective than multiple regression in parsimonious model testing for management development research. Journal of Management Development, 20 , $650-667$.

Cheung, G. W., \& Rensvold, R. B. (2000). Assessing extreme and acquiesence response sets in cross-cultural research using SEM. Journal of Cross-Cultural Psychology, 31, $187-212$.

Corrigall, E. A., \& Konrad, A. M. (2006). The relationship of job attribute preferences to employment, hours of paid work, and family responsibilities: An analysis comparing women and men. Sex Roles, 54, 95-111.

Diener, E., Emmons, R. A., Larsen, R. J., \& Griffin, S. (1985). The satisfaction with life scale. Journal of Personality Assessment, 49, 71-75.

Duxbury, L., \& Higgins, C. (2001). Work-life balance in the new millennium: Where are we? Where do we need to go? CPRN Discussion Paper No. W/21. Ottawa: Canadian Policy Research Networks, Inc.

Eagly, A.H., \& Wood, W. (2012). Social role theory. In P.A.M. Van Lange, A.W. Kruglanski, \& E.T. Higgins (Eds.), Handbook of theories of social psychology (Vol. 2, pp. 458-476). Thousand Oaks, CA: Sage.

Eaton, S. (2003). If You Can Use Them: Flexibility Policies, Organizational Commitment, and Perceived Performance. Industrial Relations, 42(2), 145-267.

Evans, M. (1985). A Monte Carlo study of the effects of correlated method variance in moderated multiple regression analysis. Organizational Behavior and Human Decision Processes, 36(3), 305-323. 
Ferguson, M., Carlson, D., Zivnuska, S., \& Whitten, D. (2012). Support at work and home: The path to satisfaction through balance. Journal of Vocational Behavior, 80(2), 299-307.

Frone, M. R. (2003). Work-family balance. In J. C. Quick and L. E. Tetrick (Eds.), Handbook of occupational health psychology (pp. 143-162). Washington, DC: American Psychological Association.

Grace, J. B., \& Bollen, K. A. (2005). Interpreting the results from multiple regression and structural equation models. Bulletin of the Ecological Society of America, 86, 283-295.

Greenhaus, J., \& Allen, T. (2011). Work-family balance: A review and extension of the literature. In J. C. Quick and L. E. Tetrick (Eds.), Handbook of occupational health psychology ( $2^{\text {nd }}$ edition). Washington, DC: American Psychological Association.

Greenhaus, J. H., Collins, K. M., \& Shaw, J. D. (2003). The relation between work-family balance and quality of life. Journal of Vocational Behavior, 63(3), 510-531.

Guest, D.E. (2002). Perspectives on the study of work-life balance. Social Science Information, $41,255-279$.

Gupta, V., Surie, G., Javidan, M., \& Chhokar, J. (2002). Southern Asia cluster: Where the old meets the new? Journal of World Business, 37(1), 16-27.

Haar, J. M. (2013). Testing a new measure of WLB: A study of parent and non-parent employees from New Zealand. The International Journal of Human Resource Management, 24(17/18), 3305-3324.

Haar, J. M., Roche, M., \& Taylor, D. (2012). Work-family conflict and turnover intentions of indigenous employees: The importance of the whanau/family for Maori. The International Journal of Human Resource Management, 23(12), 2546-2560.

Haar, J. \& Brougham, D. (2011). Outcomes of cultural satisfaction at work: A study of New Zealand Maori. Asia Pacific Journal of Human Resources, 49(4), 461-475.

Hall, D. T., Kossek, E. E., Briscoe, J. P., Pichler, S., \& Lee, M. D. (2013). Nonwork orientations relative to career: A multidimensional measure. Journal of Vocational Behavior, 83(3), 539-550.

Hair, J. F., Black, W. C. Babin, B. J., \& Anderson, R. E. (2010). Multivariate Data Analysis ( $7^{\text {th }}$ edition). New York: Pearson Prentice Hall.

Hammer, L. B., Kossek, E. E., Anger, W. K., Bodner, T., \& Zimmerman, K. (2011). Clarifying work-family intervention processes: The roles of work-family conflict and family supportive supervisor behaviors. Journal of Applied Psychology, 96, 134-150.

Hill, E., Yang, C., Hawkins, A., \& Ferris, M. (2004). A cross-cultural test of the work-family interface in 48 countries. Journal of Marriage and the Family, 66(5), 1300-1316. 
House, R. J., Hanges, P. J., Javidan, M., Dorfman, P. W., \& Gupta, V. (Eds.). (2004). Culture, leadership, and organizations: The GLOBE Study of 62 Societies. Thousand Oaks: Sage Publications.

Iacobucci, D., Saldanha, N., \& Deng, Z. (2007). A meditation on mediation: Evidence that structural equations models perform better than regressions. Journal of Consumer Psychology, 17, 139-153.

Judge, T. A., Bono, J. E., Erez, A., \& Locke, E. A. (2005). Core self-evaluations and job and life satisfaction: The role of self-concordance and goal attainment. Journal of Applied Psychology, 90(2), 257-268.

Kenny, D. A. (2008). Reflections on mediation. Business Research Methods, 11(2), 353-358.

Kossek, E. E., \& Ollier-Malaterre, A. (2013). Work-family policies: Linking national contexts, organizational practice and people for multi-level change. In S. A. Y. Poelmans, J. H. Greenhaus, \& M. Las Heras Maestro (Eds.), Expanding the Boundaries of Work-Family Research: A Vision for the Future (pp. 3-30). United Kingdom: Palgrave.

Kossek, E. E., Valcour, M., \& Lirio, P. (2014). The Sustainable Workforce: Organizational Strategies for Promoting Work-Life Balance and Well-Being. In C. Cooper \& P. Chen (Eds.), Work and Wellbeing (pp. 295-318), Oxford, UK: Wiley-Blackwell.

Kossek, E. E., Baltes, B. B., \& Matthews, R. A. (2011). How work-family research can finally have an impact in the workplace. Industrial and Organizational Psychology: Perspectives on Science and Practice, 4, 352-369.

Larson, R., Verma, S., \& Dworkin, J. (2001). Men's work and family lives in India: The daily organization of time and emotion. Journal of Family Psychology, 15(2), 206-224.

Lu, L., Cooper, C. L., Kao, S.-F., Chang, T.-T., Allen, T. D., Lapierre, L. M., O'Driscoll, M. P., Poelmans, S. A. Y., Sanchez, J. I., \& Spector, P. E. (2010). Cross-cultural differences on work-to-family conflict and role satisfaction: A Taiwanese-British comparison. Human Resource Management, 49(1), 67-85.

Lu, L., Gilmour, R., Kao, S. F., \& Huang, M. T. (2006). A cross-cultural study of work/family demands, work/family conflict and wellbeing: The Taiwanese vs. British. Career Development International, 11, 9-27.

Lunau, T., Bambra, C., Eikemo, T. A., van der Wel, K. A., \& Dragano, N. (2014). A balancing act? Work-life balance, health and well-being in European welfare states. European Journal of Public Health. doi: 10.1093/eurpub/cku010

Lyness, K.S. \& Judiesch, M.K. (2014). Gender Egalitarianism and Work-Life Balance for Managers: Multisource Perspectives in 36 Countries, Applied Psychology, 63(1), 96-129. 
Lyness, K.S., \& Judiesch, M.K. (2008). Can a manager have a life and a career? International and multisource perspectives on work-life balance and career advancement potential. Journal of Applied Psychology, 93, 789-805.

Lyness, K. S., \& Kropf, M. B. (2005). The relationships of national gender equality and organizational support with work-family balance: A study of European managers. Human Relations, 58, 33-60.

Maertz, C.P., \& Boyar, S.L. (2011). Work-family conflict, enrichment, and balance under 'levels'and 'episode' approaches. Journal of Management, 37(1), 68-98.

Marks, S.R., \& MacDermid, S.M. (1996). Multiple roles and the self: A theory of role balance. Journal of Marriage and the Family, 58, 417-432.

Marsh, N. (2010, May). Nigel Marsh: How to make work-life balance work [video file]. Retrieved from https://www.ted.com/talks/nigel_marsh_how_to_make_work_life_balance_work\#t-3923

Meade, A. W., \& Kroustalis, C. M. (2006). Problems with item partialing for confirmatory factor analytic tests of measurement invariance. Organizational Research Methods, 9, 369-403.

Ollier-Malaterre, A., Valcour M., den Dulk, L., \& Kossek, E.E. (2013). Theorizing national context to develop comparative work-life research: Building bricks and research agenda. European Management Journal, 31(5), 433-447.

Ollier-Malaterre, A. (2014). Cross-national work-life research: A review at the individual level. In T. D. Allen, \& L. E. Eby (Eds.), Oxford Handbook of Work and Family.

Podsiadlowski, A., \& Fox, S. (2011). Collectivist value orientations among four ethnic groups: Collectivism in the New Zealand context. New Zealand Journal of Psychology, 40(1), 518.

Poelmans, S., Spector, P.E., Cooper, C.L., Allen, T.D., O’Driscoll, M., \& Sanchez, J.I. (2003). A Cross-National Comparative Study of Work/Family Demands and Resources. International Journal of Cross Cultural Management, 3(3), 275-288.

Poelmans, S. (2005). Work and family. An international research perspective. New Jersey: Lawrence Erlbaum Associates.

Powell, G. N., Francesco, A. M., \& Ling, Y. (2009). Towards culture-sensitive theories of the work-family interface. Journal of Organizational Behaviour, 30(5), 597-616.

Ramamoorthy, N., \& Flood, P. C. (2002). Employee attitudes and behavioral intentions: A test of the main and moderating effects of individualism-collectivism orientations. Human Relations, 55(9), 1071-1096. 
Redding, S.G., \& Wong, G.Y.Y. (1986). The psychology of Chinese organizational behaviour. In M. H. Bond (Ed.), The psychology of the Chinese people (pp.267-295). New York: Oxford University Press

Redding, S.G. (1993). The spirit of Chinese capitalism. New York: de Gruyter.

Rothbard, N.P. (2001). Enriching or Depleting? The Dynamics of Engagement in Work and Family Roles. Administrative Science Quarterly, 46(4), 655-684

Schmitt, N. \& Kuljanin, G. (2008). Measurement invariance: review of practice and implications. Human Resource Management Review, 18(4), 210-222.

Shaffer, M. A., Joplin, J. R. W., \& Hsu, Y. S. (2011). Expanding the boundaries of work-family research: A review and agenda for future research. International Journal of Cross Cultural Management, 11(2), 221-268.

Spector, P. E., Cooper, C. L., Poelmans, S. A. Allen, T. D., O'Driscoll, M., Sanchez, J. I., Siu, O. L., Dewe, P., Hart, P., \& Lu, L. (2004). A cross-national comparative study of workfamily stressors, working hours, and well-being: China and Latin America versus the Anglo world. Personnel Psychology, 57(1), 119-142.

Spector, P. E., Allen, T. D., Poelmans, S. A. Y., Lapierre, L. M., Cooper, C. L., O'Driscoll, M., et al. (2007). Cross-national differences in relationships of work demands, job satisfaction, and turnover intentions with work-family conflict. Personnel Psychology, 60(4), 805-835.

Spell, C. S., \& Arnold, T. J. (2007). A multi-level analysis of organizational justice climate, structure, and employee mental health. Journal of Management, 33(5), 724-751.

Taras, V., Rowney, J., \& Steel, P. (2009). Half a century of measuring culture: Approaches, challenges, limitations and suggestions based on the analysis of 112 instruments for quantifying culture. Journal of International Management, 15(4), 357-373.

Triandis, H. C. (1995). Individualism and Collectivism. Boulder, CO: Westview.

Triandis, H. C., Leung, K., Villareal, M. J., \& Clack, F. L. (1985). Allocentric versus idiocentric tendencies: Convergent and discriminant validation. Journal of Research in Personality, 19(4), 395-415.

Trompenaars, A., \& Hampden-Turner, C. (1998). Riding The Waves of Culture: Understanding Diversity in Global Business. New York: McGraw Hill.

Valcour, M. (2007). Work-based resources as moderators of the relationship between work hours and satisfaction with work-family balance. Journal of Applied Psychology, 92(6), 1512-1523. 
Wang, P., Lawler, J. J., Walumbwa, F. O., \& Shi, K. (2004). Work-family conflict and job withdrawal intentions: The moderating effect of cultural differences. International Journal of Stress Management, 11(4), 392-412.

Williams, L. J., Vandenberg, R. J., \& Edwards, J. R. (2009). 12 Structural equation modelling in management research: A guide for improved analysis. The Academy of Management Annals, 3(1), 543-604.

Wood, W., \& Eagly, A. H. (2002). A cross-cultural analysis of the behavior of women and men: Implications for the origins of sex differences. Psychological Bulletin, 128(5), $699-727$.

Yang, N., Chen, C. C., Choi, J., \& Zou, Y. (2000). Sources of work-family conflict: A Sino-US comparison of the effects of work and family demands. Academy of Management Journal, 43(1), 113-123. 
Table 1. Overall Study Demographics

\begin{tabular}{|c|c|c|c|c|c|c|c|c|}
\hline \multirow[b]{2}{*}{ Country } & \multicolumn{3}{|c|}{ Demographics } & \multicolumn{4}{|c|}{ Sector } & \multirow[b]{2}{*}{$\begin{array}{l}\text { Not-for- } \\
\text { Profit }\end{array}$} \\
\hline & $\mathbf{N}$ & $\begin{array}{l}\text { Age } \\
\text { (Years) }\end{array}$ & $\begin{array}{l}\text { Gender } \\
\text { (Female) }\end{array}$ & Married & Parent & Private & Public & \\
\hline New Zealand & 366 & 34.3 & $55 \%$ & $70 \%$ & $51 \%$ & $56 \%$ & $40 \%$ & $4 \%$ \\
\hline New Zealand Maori & 335 & 38.9 & $63 \%$ & $67 \%$ & $69 \%$ & $22 \%$ & $70 \%$ & $8 \%$ \\
\hline France & 139 & 39.2 & $62 \%$ & $80 \%$ & $74 \%$ & $74 \%$ & $22 \%$ & $4 \%$ \\
\hline Italy & 238 & 44.0 & $43 \%$ & $69 \%$ & $60 \%$ & $63 \%$ & $35 \%$ & $2 \%$ \\
\hline Spain & 127 & 39.7 & $50 \%$ & $78 \%$ & $66 \%$ & $62 \%$ & $36 \%$ & $2 \%$ \\
\hline Malaysia & 110 & 32.1 & $48 \%$ & $75 \%$ & $63 \%$ & $4 \%$ & $96 \%$ & $0 \%$ \\
\hline China & 101 & 31.4 & $63 \%$ & $47 \%$ & $43 \%$ & $45 \%$ & $38 \%$ & $17 \%$ \\
\hline Total Sample & \multicolumn{8}{|c|}{1416} \\
\hline Collectivistic: & \multicolumn{8}{|c|}{ Maori, Malaysia and China $(n=546)$} \\
\hline Average Age & \multicolumn{8}{|c|}{37.6 years $(\mathrm{SD}=11.5$ Years $)$} \\
\hline Gender & \multicolumn{8}{|c|}{$55 \%$ female } \\
\hline Married & \multicolumn{8}{|c|}{$70 \%$} \\
\hline Parents & \multicolumn{8}{|c|}{$61 \%$} \\
\hline Industry: & \multicolumn{8}{|c|}{$46.8 \%$ Private } \\
\hline & \multicolumn{8}{|c|}{ 48.5\% Public } \\
\hline & \multicolumn{8}{|c|}{$4.6 \%$ Not-For-Profit } \\
\hline
\end{tabular}


Table 2. Results of Exploratory Factor Analysis for WLB

\begin{tabular}{|c|c|c|c|c|c|c|c|c|}
\hline \multirow[b]{2}{*}{$\begin{array}{l}\text { Responses were coded } 1=\text { strongly } \\
\text { disagree, } 5=\text { strongly agree }\end{array}$} & \multicolumn{8}{|c|}{ Factor Loadings for each Country } \\
\hline & $\mathbf{N Z}$ & $\begin{array}{l}\text { NZ } \\
\text { Maori }\end{array}$ & France & Italy & Spain & Malaysia & China & Combined \\
\hline $\begin{array}{l}\text { 1. I am satisfied with my WLB, } \\
\text { enjoying both roles }\end{array}$ & .847 & .906 & .875 & .873 & .801 & .912 & .907 & .874 \\
\hline $\begin{array}{l}\text { 2. Nowadays, I seem to enjoy every } \\
\text { part of my life equally well }\end{array}$ & .866 & .904 & .842 & .870 & .841 & .882 & .809 & .875 \\
\hline $\begin{array}{l}\text { 3. I manage to balance the demands } \\
\text { of my work and personal/family } \\
\text { life well }\end{array}$ & .821 & .883 & .910 & .800 & .886 & .916 & .867 & .860 \\
\hline Number of items in measure & \multicolumn{8}{|c|}{ All analyses confirmed a one factor 3-item measure } \\
\hline Eigenvalues & 2.141 & 2.471 & 2.304 & 2.159 & 2.134 & 2.450 & 2.230 & 2.267 \\
\hline Percentage variance & $71.4 \%$ & $80.6 \%$ & $76.8 \%$ & $72.0 \%$ & $71.1 \%$ & $81.7 \%$ & $74.3 \%$ & $75.6 \%$ \\
\hline Cronbach's Alpha & .80 & .88 & .85 & .80 & .80 & .89 & .83 & .84 \\
\hline
\end{tabular}


Table 3. Means, Standard Deviations and Correlations of Model Variables

\begin{tabular}{|c|c|c|c|c|c|c|c|c|c|c|c|}
\hline & $\mathbf{M}$ & SD & 1 & 2 & 3 & 4 & 5 & 6 & 7 & 8 & 9 \\
\hline 1. Work-Life Balance & 3.4 & .84 & .84 & & & & & & & & \\
\hline 2. Work-Family Conflict & 2.9 & 1.0 & $-.40 * *$ & .87 & & & & & & & \\
\hline 3. Family-Work Conflict & 2.3 & .79 & $-.15 * *$ & $.36 * *$ & .77 & & & & & & \\
\hline 4. Collectivism & 4.9 & .85 & $.08 * *$ & .00 & $.10^{* *}$ & -- & & & & & \\
\hline 5. Gender Egalitarianism & 4.2 & .46 & $-.09 * *$ & .02 & $-.05^{*}$ & $-.38 * *$ & -- & & & & \\
\hline 6. Job Satisfaction & 3.6 & .72 & $.36 * *$ & $-.15 * *$ & $-.13 * *$ & -.02 & $.18 * *$ & .79 & & & \\
\hline 7. Life Satisfaction & 3.4 & .74 & $.47 * *$ & $-.18 * *$ & $-.09 * *$ & .03 & -.05 & $.43 * *$ & .83 & & \\
\hline 8. Anxiety & 2.7 & 1.0 & $-.34 * *$ & $.22 * *$ & $.12 * *$ & $-.14 * *$ & $.34 * *$ & $-.27 * *$ & $-.36 * *$ & .88 & \\
\hline 9. Depression & 2.4 & .92 & $-.34 * *$ & $.15^{* *}$ & $.09 * *$ & $-.14 * *$ & $.15^{* *}$ & $-.42 * *$ & $-.39 * *$ & $.63 * *$ & .87 \\
\hline
\end{tabular}

$\mathrm{N}=1416,{ }^{*} \mathrm{p}<.05, * * \mathrm{p}<.01$. (Cronbach's alpha reported on diagonal line in italics)

\section{Table 4. Final Structural Models Results (Combined Data)}

\begin{tabular}{|c|c|c|c|c|}
\hline & \multicolumn{4}{|c|}{ Outcomes } \\
\hline & Job Satisfaction & Life Satisfaction & Anxiety & Depression \\
\hline \multicolumn{5}{|l|}{ Model 1: } \\
\hline Work-Life Balance & $.50 * * *$ & $.52 * * *$ & $-.37 * * *$ & $-.38 * * *$ \\
\hline Collectivism & .00 & -.02 & $-.10 * * *$ & $-.10 * * *$ \\
\hline Work-Life Balance x Collectivism & $-.12 * * *$ & $-.11 * * *$ & .06 & .05 \\
\hline Total $\mathbf{R}^{2}$ & .25 & .33 & .18 & .18 \\
\hline \multicolumn{5}{|l|}{ Model 2: } \\
\hline Gender Egalitarianism & $.08 * * *$ & -.02 & $.29 * * *$ & $.10 * * *$ \\
\hline Work-Life Balance x Gender Egalitarianism & $.05 *$ & $.10 * * *$ & $-.09 * *$ & -.02 \\
\hline Total $\mathbf{R}^{2}$ & .25 & .33 & .28 & .18 \\
\hline
\end{tabular}

Unstandardized regression weights, only main effects are shown. We controlled for gender, work-family conflict and family-work conflict directly on the DVs, and these three control variables covary on WLB. Similarly, all four DVs covary.

$* \mathrm{p}<0.05, * * \mathrm{p}<.01, * * * \mathrm{p}<.001$ 
Table 5. Direct Effects Structural Models Results (Individual Samples)

\begin{tabular}{|c|c|c|c|c|c|c|c|}
\hline & \multirow[b]{2}{*}{$\begin{array}{c}\text { New Zealand } \\
\text { Maori: }\end{array}$} & \multicolumn{6}{|c|}{ Outcomes } \\
\hline & & $\begin{array}{c}\text { New Zealand } \\
\text { European }\end{array}$ & France & Italy & Spain & Malaysia & China \\
\hline \multicolumn{8}{|l|}{ Job Satisfaction } \\
\hline Work-Life Balance & $.26 * * *$ & $.67 * * *$ & $.58 * * *$ & $.57 * * *$ & $.48 * * *$ & $.55 * * *$ & $.59 * * *$ \\
\hline Total $\mathbf{R}^{2}$ & .13 & .42 & .22 & .72 & .15 & .41 & .40 \\
\hline \multicolumn{8}{|l|}{ Life Satisfaction: } \\
\hline Work-Life Balance & $.21 * * *$ & $.66^{* * *}$ & $.65 * * *$ & $.73 * * *$ & $.49 * * *$ & $.34 * * *$ & $.66^{* * *}$ \\
\hline Total $\mathbf{R}^{2}$ & .12 & .39 & .58 & .40 & .36 & .32 & .47 \\
\hline \multicolumn{8}{|l|}{ Anxiety: } \\
\hline Work-Life Balance & $-.17 * * *$ & $-.40 * * *$ & $-.26 *$ & $-.39 * * *$ & $-.34 * * *$ & $-.42 * *$ & $-.19 \dagger$ \\
\hline Total $\mathbf{R}^{2}$ & .09 & .26 & .16 & .19 & .24 & .26 & .12 \\
\hline \multicolumn{8}{|l|}{ Depression: } \\
\hline Work-Life Balance & $-.25 * * *$ & $-.46^{* * *}$ & $-.39 * *$ & $-.37 * * *$ & $-.32 * *$ & $-.64 * *$ & $-.34 * *$ \\
\hline Total $\mathbf{R}^{2}$ & .11 & .23 & .10 & .21 & .12 & .33 & .15 \\
\hline
\end{tabular}


Figure 1. General study model: Outcomes of WLB across cultures

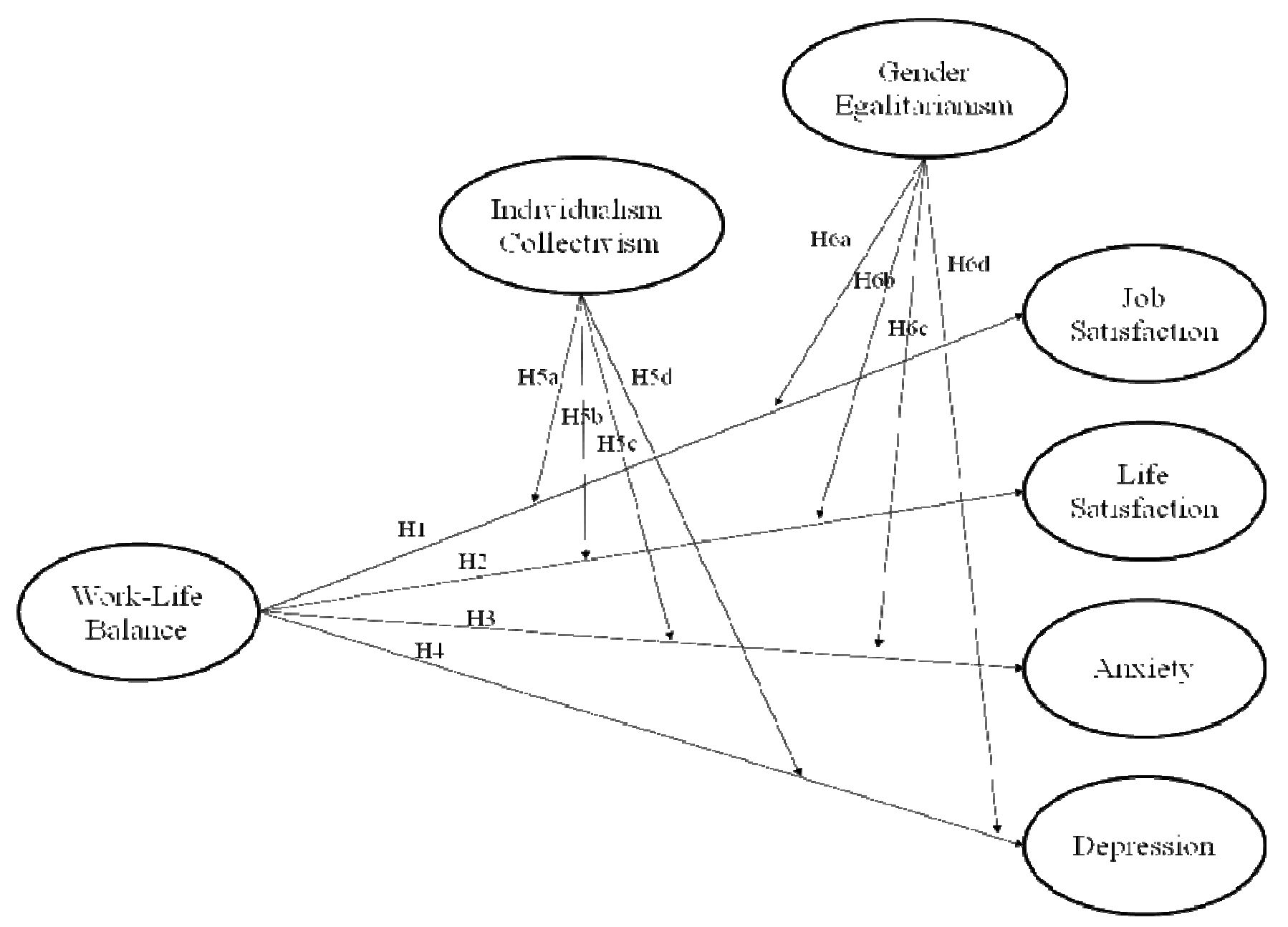


Figure 2. Interaction between WLB and I/C on Job and Life Satisfaction

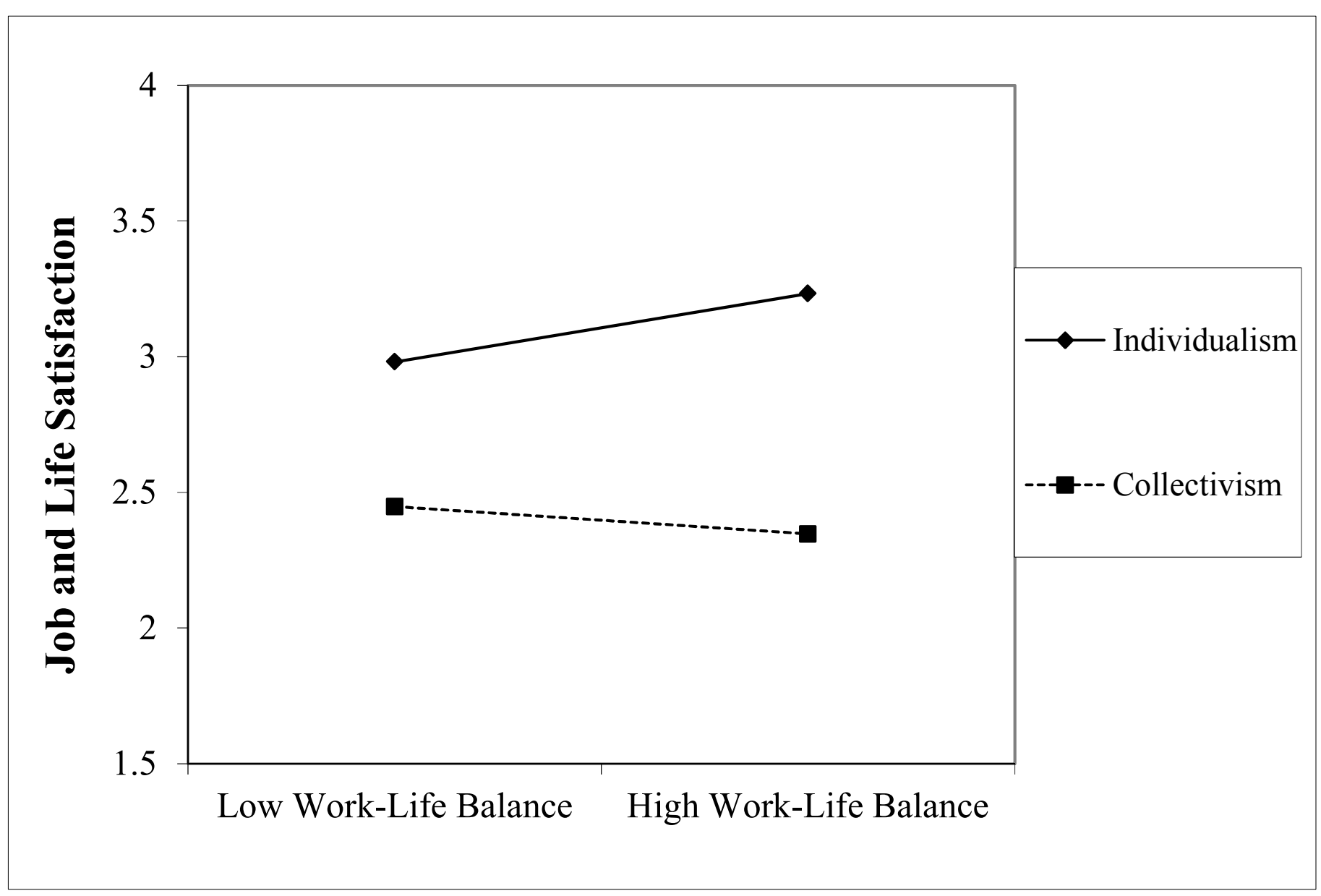


Figure 3. Interaction between WLB and Gender Egalitarianism on Job and Life Satisfaction

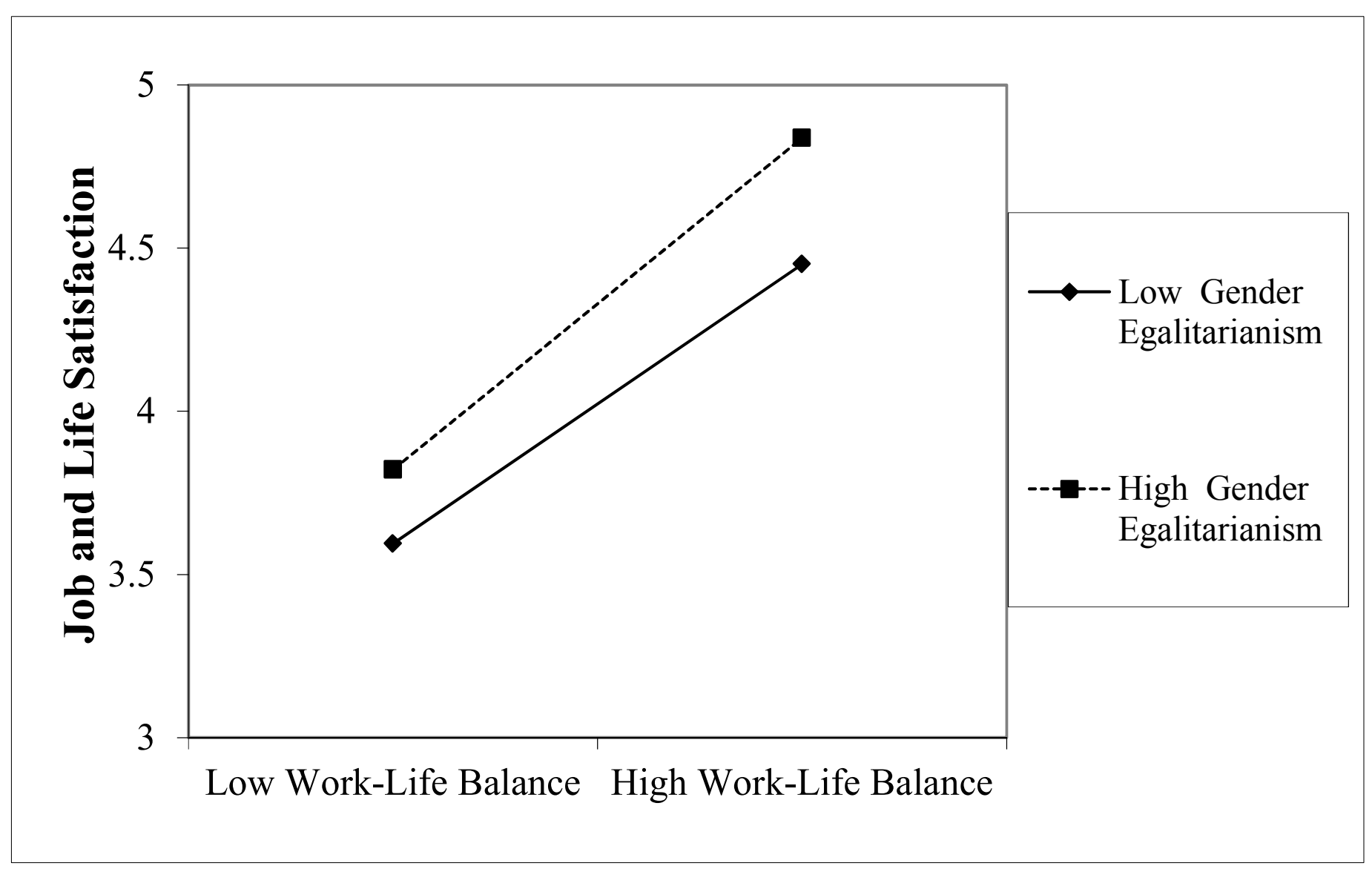


Figure 4. Interaction between WLB and Gender Egalitarianism on Anxiety

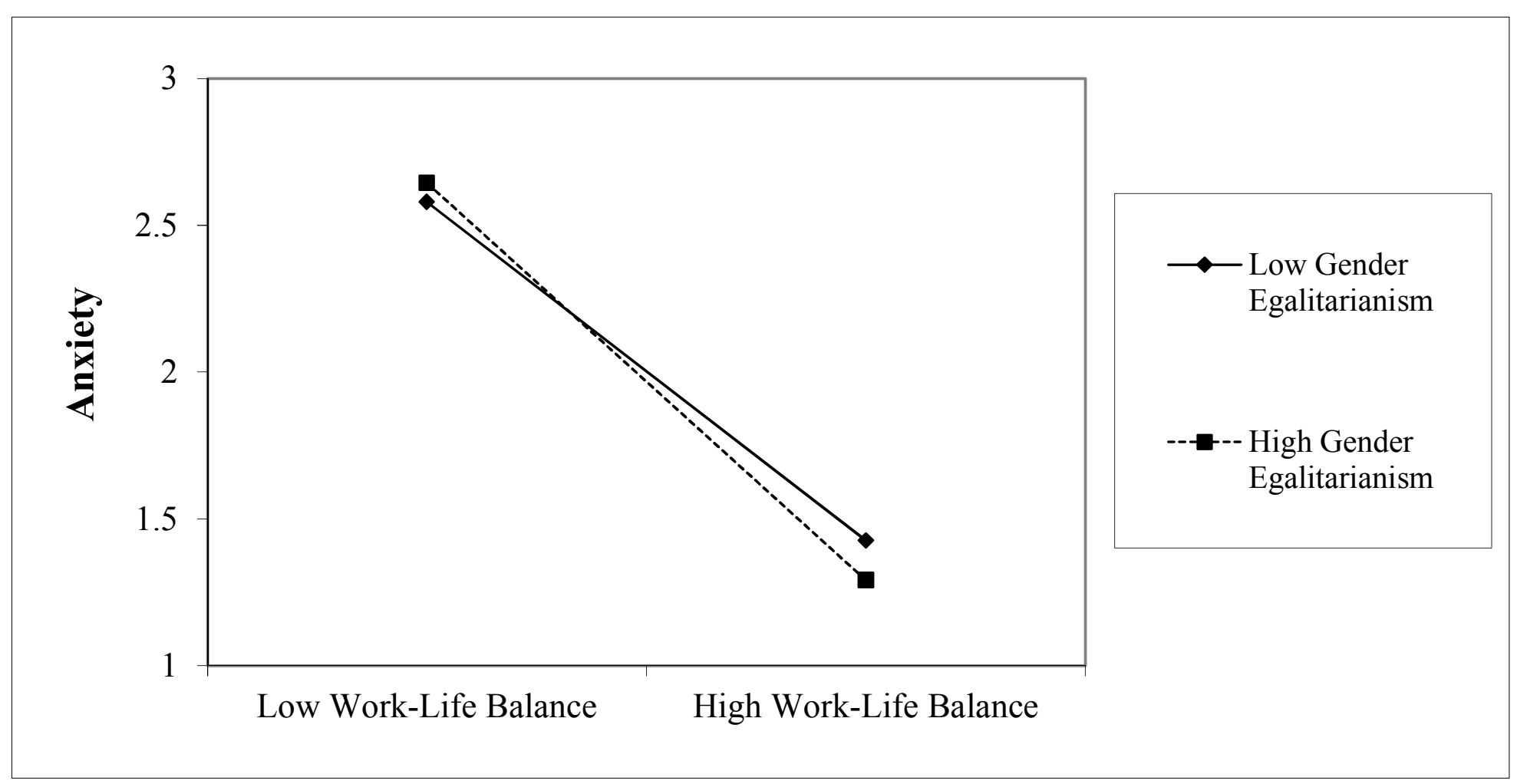

